\title{
Work-life conflict and health among Swiss physicians - in comparison with other university graduates and with the general Swiss working population
}

\section{Journal Article}

Author(s):

Knecht, Michaela; Bauer, Georg F.; Klaghofer, Richard; Buddeberg-Fischer, Barbara; Stamm, Martina; Hämmig, Oliver

Publication date:

2010-07-07

Permanent link:

https://doi.org/10.3929/ethz-b-000159276

Rights / license:

Creative Commons Attribution-NonCommercial-NoDerivatives 4.0 International

Originally published in:

Swiss Medical Weekly 140, https://doi.org/10.4414/smw.2010.13063 


\title{
Work-life conflict and health among Swiss physicians - in comparison with other university graduates and with the general Swiss working population
}

\author{
Michaela Knecht ${ }^{a}$, Georg F. Bauer ${ }^{a}$, Richard Klaghofer ${ }^{b}$, Barbara Buddeberg-Fischer $^{b}$, Martina Stamm $^{b}$, Oliver Hämmig $^{a}$ \\ ${ }^{a}$ Division of Public \& Organizational Health, Institute for Social and Preventive Medicine, University of Zurich, and Center of Organizational and \\ Occupational Sciences, ETH Zurich, Switzerland \\ ${ }^{\mathrm{b}}$ Department of Psychosocial Medicine, Zurich University Hospital, Switzerland
}

\author{
Correspondence: \\ Michaela Knecht \\ Hirschengraben 84 \\ $\mathrm{CH}-8001$ Zürich \\ E-Mail: michaela.knecht@ifspm.uzh.ch
}

\section{Summary}

Question under study: The present study aimed to compare the prevalence of work-life conflict and the health status of physicians, with a representative sample of university graduates as well as with a representative sample of the general Swiss working population. Furthermore, it aimed to analyse whether work-life conflict correlates with the health of physicians, as it does in the general working population.

Methods: The present cross-sectional study analysed data from 2007 originating from the SwissMedCareer Study (a prospective cohort study of physicians who graduated in 2001; $\mathrm{n}=543$ ) and the Swiss Household Panel (a representative Swiss survey on living and working conditions; university graduates of the same age range: $n=172$, general working population of the same age range: $n=$ 670). Data were analysed with $\mathrm{Chi}^{2}$ tests, correlations and logistic regressions.

Results: Physicians reported strong time-based as well as strain-based work-life conflicts more frequently than university graduates and the general working population. Significantly more physicians reported "moderate" to "very poor" health than the other two samples. Surprisingly, on the other side of the scale ("very good" health), physicians outnumbered the other samples too. Strong associations between work-life conflict and self-rated health as well as various health complaints were found for physicians.

Conclusion: The high prevalence of work-life conflict may explain the comparably high prevalence of poor selfrated health in the physicians' sample.
Key words: Work-life conflict; work-family conflict; health; physicians; university graduates; Switzerland

\section{Introduction}

Juggling work and family has become more prevalent during the last three decades, in the course of several major social changes such as an increasing number of women joining the workforce, more working single parents and more dual-income families, just to mention a few factors. These developments have increased the number of employees who face substantial domestic duties as well as work obligations [1]. These general social changes apply in particular to physicians, a profession in which a strong "feminisation" is taking place [2]. In the USA, the percentage of women physicians almost tripled between 1979 and 2002 [3]. In Germany, the proportion of female medical graduates has increased to over $50 \%$ in the last 20 years [4]. In Switzerland, the proportion of female medical graduates rose from $22 \%$ in 1977 to $58 \%$ in 2007 [5]. Accordingly, the percentage of females in the medical profession rose from $17 \%$ to $34 \%$ during the same time period [6].

The competing demands of different life domains can generate inter-role conflicts. Greenhaus [7] defined this as a work-family conflict, thus introducing a classification which describes three different forms of conflict. Timebased conflict is experienced when obligations associated with one role prevent one from fulfilling obligations from another role. Strain-based conflict is experienced when strain or fatigue from one role constrains one's performance in another role. The third form, behavioural-based conflict, occurs when behavioural patterns in one role are incompatible with the requirements of another role. This latter form of work-family conflict has been difficult to operationalise, so there is little empirical evidence available for its existence [8]. Conflicts between family and work may derive from either work interfering with family life (e.g. one's work schedule interferes with family activities) or from family demands interfering with work obliga- 
tions (e.g. illness of a family member interferes with concentration at work) [8], and is therefore bidirectional [9]. The present study widens the focus from work-family conflict to work-life conflict, including other aspects of one's private life besides children and marriage.

A great number of studies have identified severe consequences of work-family conflict [10], which can be classified into three categories: work-, family- and general stress-related consequences [10]. The present study focuses on health outcomes as part of general stress-related outcomes. As international research has shown, work-family conflict is associated with poor mental and physical health [11-13].

Work-life conflict has been found to be significantly associated with workload in a number of studies [14-17]. Due to the high workload in many physicians' jobs, such as long working hours, long working days, high job demands and high emotional demands [18, 19], physicians are expected to be a risk group for work-life conflict and consequently for health problems. Therefore, several international studies have analysed work-life conflict among physicians [4, 19-22]. Since different measures have been used, no comparison is possible between the prevalence in the different studies or with samples of other occupations. Only one study analysing German hospital physicians compared the results with non-physicians. It showed that worklife conflict among physicians is significantly stronger than in the general German population [4]. No study has been carried out in Switzerland comparing physicians' work-life conflict to reference samples in the Swiss population [23].

Also, beyond work-life conflict research, the issue of physicians' health has been of interest in several studies [24-31], particularly because of concerns for quality in the healthcare system [27]. The results have not been consistent. Several studies showed high levels of health complaints [4, 32], whereas others reported fewer health problems for physicians than for other university graduates or people with a lower education level [33]. Työry et al. [24] found a lower than average prevalence of specific diseases such as hypertension and chronic bronchitis for female physicians, whereas male physicians did not differ from the general population in this respect.

As for employees in general, an association between health and work-life conflict was also found for physicians $[4,19,20,22]$. Whereas most of these studies concentrated only on very specific aspects of health, such as burnout or psychosomatic complaints, one study only analysed selfrated health in general. International studies cannot be generalised to Switzerland, since the situation in the healthcare system and therefore the working conditions of physicians in Switzerland differ in several respects from those in other countries, such as in terms of working hours, payment and organisation of hospitals. The present study aimed to fill this gap.

\section{Study aim and research questions}

The present study aimed to assess the prevalence of worklife conflict in a sample of Swiss physicians and to compare it in this respect with the general working population and other university graduates. The study additionally examined the relationship between work-life conflict and health in these different samples. The following research questions were addressed:

1. Are time-based and strain-based work-life conflicts in the sample of Swiss physicians more prevalent than among other university graduates and the working population in general? Are there gender differences in these three samples in terms of prevalence rates?

2. Does the health status of physicians differ from that of other university graduates or from the working population in general? Are there gender differences in these samples in terms of health status?

3. Is work-life conflict associated with health problems in the physicians' sample to the same extent as it is in the working population in general?

\section{Methods}

\section{Databases and study samples}

To compare the physicians with university graduates and with the general working population, the present study analysed data from the SwissMedCareer Study (SMC) and the Swiss Household Panel (SHP). The SMC is an ongoing prospective cohort study of physicians who graduated from the three medical schools in German-speaking Switzerland (Basel, Bern, Zurich), which began in 2001 (t1). The present cross-sectional analysis includes data from measuring point $t 4$ in $2007(\mathrm{n}=543$; physicians who graduated in 2001). By t4, they had worked as residents for five to six years. The SHP is a representative survey, which constitutes of a unique database in Switzerland covering a broad range of topics on living and working conditions as well as various aspects of health and well-being. The panel survey has been conducted every year since 1999 and is still ongoing. For this study, data from wave 2007 were used, including only employees in the same age range as that of the physicians. The sample of the SHP was divided into two nested subsamples, employees in general and university graduates aged from 31 to 38 years, since $95 \%$ of the physicians are between 31 and 38 years old. Table 1 gives an overview of the three samples.

\section{Measures}

Since the SHP covers a wide range of topics for annual data collection with the same group of participants, the number of questions for each topic had to be kept to a minimum. The SHP consequently chose to use mainly single-item measures with differentiated response categories (mostly 11-point Likert-type scaled items). To allow the samples to be compared, the SHP items were adopted in the SMC study.

\section{Work-life conflict}

Work-life conflict was rated by two questions, whereby one assessed time-based and the other strain-based work-to-life conflict. Both of them are adapted items translated from an established 18-item scale [34] which focuses on workfamily conflict. This focus has been broadened in the SHP to work-life conflict. The direction of life-to-work conflict was not assessed explicitly in the SHP.

Time-based work-to-life conflict was assessed by questioning: "How strongly does your work interfere with your 
private activities and family obligations: Does it do so more than you would like?"

Strain-based work-life conflict was recorded with the question: "To what extent are you too exhausted after work to do things you would like to do?"

Both were 11-point Likert-type scaled items with answer options ranging from 0 "Not at all" to 10 "Extremely strongly", which were categorised into Weak (0-3), Medium (4-6) and Strong (7-10) conflicts.

\section{Health}

To examine health effects, the 5-point single item for selfrated health [35], to which reference is often made, was used: "How is your health in general?" with the answer options "Very good", "Good", "Moderate", "Poor", and "Very poor". Single-item measures for health are widely used. They have been shown to be strong predictors of mortality, hospitalisation, and physicians' assessments of overall health, and are often a more useful outcome in stress studies than measures of specific diseases [36]. In addition to this general self-rated health item, three physical and/or psychosomatic complaints were also assessed: "Have you had any of the following types of pain or medical complaints in the last 4 weeks?" which were Back pain, Sleeping problems and Headache with three answer options (Yes, Serious/Yes, a little/No, not at all).

\section{Statistics}

Both the samples and gender differences were compared using $\mathrm{Chi}^{2}$ tests. The association between work-life conflict and health was calculated with nonparametric correlations and logistic regressions. The data analysis was conducted with SPSS Version 16.0. Significance levels of $p<.001, p$ $<.01$ and $p \leq .05$ were reported.

\section{Results}

\section{Research question 1 - Work-life conflict}

Table 2 shows the percentage of men and women experiencing strong work-life conflict (i.e. scores between 7 and 10 on the 0 to 10 scale). In the physicians' and university graduates' samples, no significant gender differences were found, whereas in the sample of the general working population men reported strong time-based work-life conflict more often $\left(\mathrm{Chi}^{2}=5.98, \mathrm{df}=1, p \leq .5\right) . \mathrm{Chi}^{2}$ tests showed that significantly more physicians reported strong timebased as well as strain-based work-life conflict than university graduates (time-based: $\mathrm{Chi}^{2}=8.30, \mathrm{df}=1, p<.01$; strain-based: $\mathrm{Chi}^{2}=7.96, \mathrm{df}=1, p<.01$ ) or employees in general (time-based: $\mathrm{Chi}^{2}=72.64, \mathrm{df}=1, p<.001$; strain- based: $\left.\mathrm{Chi}^{2}=56.64, \mathrm{df}=1, p<.001\right)$. Almost every second physician reported strong work-life conflicts compared to about one third of university graduates and one fifth of the general working population.

\section{Research question 2 - Health}

Table 2 shows the proportion of people with moderate to very poor self-rated health and serious health complaints. No significant gender differences were found in either sample concerning self-rated health. With regard to serious health complaints, such as back pain, sleeping problems and headaches, there was a tendency for more complaints among women, although only one result differed in a statistically significant way (i.e. headache in the sample of the general working population; $\mathrm{Chi}^{2}=13.82, \mathrm{df}=1, p<.001$ ). The other tests did not show any significant results, probably due to small numbers.

A higher percentage of physicians reported moderate to very poor health $(16.6 \%)$ than university graduates $(5.8 \%)$ $\left(\mathrm{Chi}^{2}=12.57, \mathrm{df}=1, p<.001\right)$ or the general working population $(8.8 \%)\left(\mathrm{Chi}^{2}=16.80, \mathrm{df}=1, p<.001\right)$. On the other hand, more physicians reported very good health as well $(40.0 \%$ of physicians versus $23.8 \%$ of university graduates and $24.8 \%$ of the general working population). No significant differences were found for serious back pain and severe headaches when comparing the three samples. However, physicians reported serious sleeping problems significantly more often than university graduates of the same age group $\left(\mathrm{Chi}^{2}=4.19, \mathrm{df}=1, p \leq .05\right)$ and also more often than the general working population $\left(\mathrm{Chi}^{2}=3.84, \mathrm{df}=1, p \leq .05\right)$. Altogether, a comparison of the health outcomes between the three samples shows that these are not as distinct as for work-life conflict.

\section{Research question 3 - Work-life conflicts and health}

Physicians' self-rated ill health correlated significantly with time-based $(\mathrm{r}=.267, p<.001)$ as well as with strainbased work-life conflict $(\mathrm{r}=.363, p<.001)$. No significant correlations were found for university graduates, probably due to small numbers. For the general working population, the correlation between self-rated ill health and strainbased work-life conflict is stronger $(\mathrm{r}=.224, p<.001)$ than between health and time-based work-life conflict $(\mathrm{r}=.120$, $p<.01)$.

When the two forms of work-life conflict were analysed within the same logistic regression, the influence of time-based work-life conflict on health outcomes almost disappeared, probably due to the reasonably strong correlation between the two variables of time- and strain-based work-life conflict. The strongest correlation between these

\begin{tabular}{|c|c|c|c|}
\hline & Physicians & University Graduates & General working population \\
\hline Data source & SwissMedCareer Study & Swiss Household Panel & Swiss Household Panel \\
\hline Sample size & $N=543$ & $N=172$ & $N=670$ \\
\hline Year of data collection & 2007 & 2007 & 2007 \\
\hline Mean age & 33.3 & 34.9 & 35.0 \\
\hline Age range & $29-48$ & $31-38$ & $31-38$ \\
\hline Percentage of women & $53.4 \%$ & $51.2 \%$ & $54.2 \%$ \\
\hline Selection criteria & $\begin{array}{l}\text { Finishing medical school at the University of } \\
\text { Basel, Bern or Zurich in } 2001\end{array}$ & $\begin{array}{l}\text { Currently working and holding a university degree and } \\
\text { aged between } 31 \text { and } 38\end{array}$ & $\begin{array}{l}\text { Currently working and aged } \\
\text { between } 31 \text { and } 38 \text { years }\end{array}$ \\
\hline
\end{tabular}


two types of conflict was found in the physicians' sample $(\mathrm{r}=.646, p<.001)$, and quite strong correlations were also found for the other samples (university graduates: $\mathrm{r}=.532$ $(p<.001)$; general working population: $\mathrm{r}=.567(p<.001))$.

Tables 3 and 4 show the results of the logistic regression analysis of time-based (table 3 ) and strain-based (table 4) work-life conflicts for the examined health outcomes, controlled for gender.

When analysed separately, these results suggest that both time-based and strain-based work-life conflicts may be important predictors for all the analysed health variables, although strain-based work-life conflict seem to be more strongly associated with health. Comparing the three samples, we found the highest odds ratios for the physicians, with one exception: the general working population showed higher odds ratios for back pain in the regression model with strain-based work-life conflict as the independent variable. The results for the university graduates do not show significant odds ratios due to small participant numbers and therefore wide confidence intervals. However, the same pattern was found.

Nagelkerke R-square values were between .007 and .135. The highest explained variance was found for selfrated health in the physicians' sample with strain-based work-life conflicts as the independent variable.

In all three samples, similar dose-response relationships were found; the stronger the work-life conflict, the higher the relative risk of poor self-rated health as well as serious back pain, sleeping problems and headaches. The same pattern also appeared when gender was analysed separately (not shown).

\section{Discussion}

More physicians reported strong work-life conflict than a comparable sample of university graduates and a representative sample of the general working population of the same age, in Switzerland. Almost half the physicians experienced strong work-life conflict. The same was found for both time-based and strain-based work-life conflict. This finding agrees with a study from Germany [4]. The higher prevalence of work-life conflict in the physicians' sample may have various reasons. One important cause is probably their high workload (in the form of long working days and many working hours per week) which is known as an important antecedent of strong work-life conflict [14-17, 37]. Another important cause may be their minimal autonomy at work [38]. Time-related autonomy in particular is expected to be limited in a hospital setting. Since these possible predictors of work-life conflict were not assessed in the same way in the different samples, a detailed comparison could not be made.

No gender differences, with respect to persons experiencing strong work-life conflict, were found in the physicians' sample. This is consistent with findings from Germany [4] but contradicts findings from a Hungarian study, where females reported more work-life conflict [22]. In the other two samples, men reported stronger work-life conflict than women.

The results for the differences between the three samples in the self-rated health variables are less pronounced. High education and socio-economic status usually correlate with good health. This was found in the study for the general working population and university graduates, but the physicians did not report such good self-rated

\begin{tabular}{|c|c|c|c|c|}
\hline \multicolumn{5}{|l|}{ Table 2} \\
\hline & & Men & Women & Total \\
\hline & & $n=253$ & $n=290$ & $n=543$ \\
\hline \multirow[t]{7}{*}{ Physicians $^{1}$} & Strong time-based work-life conflict $(7-10)$ & $49.2 \%$ & $44.7 \%$ & $46.8 \%$ \\
\hline & Strong strain-based work-life conflict (7-10) & $44.8 \%$ & $50.4 \%$ & $47.8 \%$ \\
\hline & Self-rated health (moderate - very poor) & $15.8 \%$ & $17.3 \%$ & $16.6 \%$ \\
\hline & Back pain (serious) & $9.9 \%$ & $11.8 \%$ & $10.9 \%$ \\
\hline & Sleeping problems (serious) & $7.1 \%$ & $11.8 \%$ & $9.6 \%$ \\
\hline & Headache (serious) & $5.1 \%$ & $9.4 \%$ & $7.4 \%$ \\
\hline & & $n=84$ & $n=88$ & $\mathrm{n}=172$ \\
\hline \multirow[t]{7}{*}{ University graduates $^{2}$} & Strong time-based work-life conflict $(7-10)$ & $39.3 \%$ & $29.5 \%$ & $34.3 \%$ \\
\hline & Strong strain-based work-life conflict (7-10) & $35.7 \%$ & $35.2 \%$ & $35.5 \%$ \\
\hline & Self-rated health (moderate - very poor) & $6.0 \%$ & $5.7 \%$ & $5.8 \%$ \\
\hline & Back pain (serious) & $8.3 \%$ & $8.0 \%$ & $8.1 \%$ \\
\hline & Sleeping problems (serious) & $3.6 \%$ & $5.7 \%$ & $4.7 \%$ \\
\hline & Headache (serious) & $2.4 \%$ & $8.0 \%$ & $5.2 \%$ \\
\hline & & $n=307$ & $n=363$ & $n=670$ \\
\hline \multirow[t]{6}{*}{ General working population ${ }^{2}$} & Strong time-based work-life conflict $(7-10)$ & $27.8 \%$ & $19.7 \%$ & $23.4 \%$ \\
\hline & Strong strain-based work-life conflict (7-10) & $27.5 \%$ & $26.2 \%$ & $26.8 \%$ \\
\hline & Self-rated health (moderate - very poor) & $8.8 \%$ & $8.8 \%$ & $8.8 \%$ \\
\hline & Back pain (serious) & $9.1 \%$ & $11.6 \%$ & $10.4 \%$ \\
\hline & Sleeping problems (serious) & $5.9 \%$ & $7.2 \%$ & $6.6 \%$ \\
\hline & Headache (serious) & $3.6 \%$ & $11.3 \%$ & $7.8 \%$ \\
\hline
\end{tabular}


health as one would expect from their education and socioeconomic status.

Significantly, more physicians reported moderate to very poor health compared with university graduates and the general working population. On the other hand, more physicians also reported very good health. With regard to health complaints, a significant difference was only found for serious sleeping problems. Possible explanations for the high percentage of physicians reporting sleeping problems might be shift work or emotionally demanding work, which physicians are often called upon to do. When the physicians' health was compared with that of the working population in general, some limitations become apparent. The self-assessment of health may be influenced by work

\begin{tabular}{|c|c|c|c|c|c|c|c|c|c|c|c|c|c|}
\hline & & $\begin{array}{l}\text { Self-rat } \\
\text { (moder }\end{array}$ & $\begin{array}{l}\text { ted heal } \\
\text { rate to } v\end{array}$ & $\begin{array}{l}\text { th } \\
\text { ery poor) }\end{array}$ & $\begin{array}{l}\text { Seriou } \\
\text { back } p\end{array}$ & & & $\begin{array}{l}\text { Serious } \\
\text { sleepin }\end{array}$ & $\begin{array}{l}\text { s } \\
\text { ig proble }\end{array}$ & ems & Serio & s head & che \\
\hline & $\mathrm{n}(\%)$ & $\%$ & OR & $95 \% \mathrm{Cl}$ & $\%$ & OR & $95 \% \mathrm{Cl}$ & $\%$ & OR & $95 \% \mathrm{Cl}$ & $\%$ & OR & $95 \% \mathrm{Cl}$ \\
\hline \multicolumn{14}{|l|}{ Physicians $^{1}$} \\
\hline \multicolumn{14}{|l|}{ Time-based WLC } \\
\hline Weak (0-3) & $137(25.6)$ & 5.1 & 1 & & 5.8 & 1 & & 4.4 & 1 & & 2.9 & 1 & \\
\hline Medium (4-6) & $148(27.4)$ & 13.5 & 2.93 & $1.20-7.18$ & 10.2 & 1.85 & $0.76-4.51$ & 6.8 & 1.64 & $0.58-4.66$ & 6.1 & 2.24 & $0.67-7.46$ \\
\hline Strong $(7-10)$ & $251(46.8)$ & 25.1 & 6.32 & $2.80-14.27$ & 13.7 & 2.59 & $1.16-5.77$ & 14.5 & 3.90 & $1.59-9.56$ & 10.8 & 4.30 & $1.47-12.61$ \\
\hline Nagelkerke R-square & & & .093 & & & .025 & & & .067 & & & .062 & \\
\hline \multicolumn{14}{|l|}{ University graduates ${ }^{2}$} \\
\hline \multicolumn{14}{|l|}{ Time-based WLC } \\
\hline Weak (0-3) & $60(34.9)$ & 6.7 & 1 & & 5.0 & 1 & & 5.0 & 1 & & & & \\
\hline Medium (4-6) & $53(30.8)$ & 9.4 & 1.43 & $0.36-5.71$ & 9.4 & 1.99 & $0.45-8.85$ & 3.8 & 0.80 & $0.13-5.02$ & & & \\
\hline Strong (7-10) & $59(34.3)$ & 1.7 & 0.24 & $0.03-2.21$ & 10.2 & 2.17 & $0.51-9.24$ & 5.1 & 1.11 & $0.21-5.83$ & & & \\
\hline Nagelkerke R-square & & & .059 & & & .018 & & & .010 & & & & \\
\hline \multicolumn{14}{|l|}{$\begin{array}{l}\text { General working } \\
\text { population }^{2}\end{array}$} \\
\hline \multicolumn{14}{|l|}{ Time-based WLC } \\
\hline Weak (0-3) & $275(41.3)$ & 6.0 & 1 & & 10.2 & 1 & & 6.0 & 1 & & 8.4 & 1 & \\
\hline Medium (4-6) & $235(35.3)$ & 10.4 & 1.76 & $0.91-3.41$ & 8.2 & 1.00 & $0.54-1.87$ & 7.1 & 1.17 & $0.56-2.46$ & 6.0 & 1.35 & $0.66-2.74$ \\
\hline Strong $(7-10)$ & $156(23.4)$ & 16.5 & 1.89 & $0.93-3.86$ & 19.6 & 2.05 & $1.12-3.76$ & 10.3 & 1.56 & $0.72-3.38$ & 13.4 & 2.27 & $1.11-4.62$ \\
\hline Nagelkerke R-square & & & .014 & & & .024 & & & .007 & & & .068 & \\
\hline
\end{tabular}

${ }^{1}$ SwissMedCareer Study t4 (2007), ${ }^{2}$ Swiss Household Panel, Year 2007

Table 4

Logistic regression from strain-based work-life conflicts for different health outcomes - controlled for gender (not controlled for age because of the small age range of all samples); significant Odds ratios (OR) bold ( $p \leq .05)$.

\begin{tabular}{|c|c|c|c|c|c|c|c|c|c|c|c|c|c|}
\hline & \multirow[b]{2}{*}{ n (\%) } & \multicolumn{3}{|c|}{$\begin{array}{l}\text { Self-rated health } \\
\text { (moderate to very poor) }\end{array}$} & \multicolumn{3}{|c|}{$\begin{array}{l}\text { Serious } \\
\text { back pain }\end{array}$} & \multicolumn{3}{|c|}{$\begin{array}{l}\text { Serious } \\
\text { sleeping problems }\end{array}$} & \multicolumn{3}{|c|}{ Serious headache } \\
\hline & & $\%$ & OR & $95 \% \mathrm{Cl}$ & $\%$ & OR & $95 \% \mathrm{Cl}$ & $\%$ & OR & $95 \% \mathrm{Cl}$ & $\%$ & OR & $95 \% \mathrm{Cl}$ \\
\hline \multicolumn{14}{|l|}{ Physicians $^{1}$} \\
\hline \multicolumn{14}{|l|}{ Strain-based WLC } \\
\hline Weak (0-3) & $142(26.5)$ & 2.1 & 1 & & 4.3 & 1 & & 2.8 & 1 & & 2.1 & 1 & \\
\hline Medium (4-6) & $138(25.7)$ & 15.9 & 8.79 & $2.57-30.12$ & 11.6 & 2.96 & $1.12-7.80$ & 6.5 & 2.41 & $0.72-8.03$ & 2.9 & 1.39 & $0.31-6.34$ \\
\hline Strong (7-10) & $256(47.8)$ & 25.4 & 15.71 & $4.84-51.05$ & 13.8 & 3.58 & $1.47-8.73$ & 15.4 & 6.12 & $2.14-17.54$ & 13.0 & 6.79 & $2.04-22.60$ \\
\hline Nagelkerke R-square & & & .135 & & & .039 & & & .090 & & & .114 & \\
\hline \multicolumn{14}{|l|}{ University graduates ${ }^{2}$} \\
\hline \multicolumn{14}{|l|}{ Strain-based WLC } \\
\hline Weak (0-3) & $48(27.9)$ & 2.1 & 1 & & 2.1 & 1 & & 4.2 & 1 & & 2.1 & 1 & \\
\hline Medium (4-6) & $63(36.6)$ & 7.9 & 4.06 & $0.46-36.02$ & 9.5 & 4.95 & $0.57-42.67$ & 4.8 & 1.20 & $0.19-7.52$ & 4.8 & 2.62 & $0.26-26.33$ \\
\hline Strong (7-10) & $61(35.5)$ & 6.6 & 3.30 & $0.36-30.57$ & 11.5 & 6.10 & $0.72-51.41$ & 4.9 & 1.22 & $0.20-7.65$ & 8.2 & 4.56 & $0.51-40.89$ \\
\hline Nagelkerke R-square & & & .034 & & & .057 & & & .009 & & & .089 & \\
\hline \multicolumn{14}{|l|}{$\begin{array}{l}\text { General working } \\
\text { population }^{2}\end{array}$} \\
\hline \multicolumn{14}{|l|}{ Strain-based WLC } \\
\hline Weak (0-3) & $229(34.3)$ & 4.4 & 1 & & 4.4 & 1 & & 5.5 & 1 & & 5.5 & 1 & \\
\hline Medium (4-6) & $260(38.9)$ & 8.1 & 2.17 & $0.97-4.86$ & 11.2 & 3.11 & $1.43-6.77$ & 6.6 & 1.23 & $0.56-2.66$ & 9.1 & 2.06 & $0.96-4.42$ \\
\hline Strong $(7-10)$ & $179(26.8)$ & 21.2 & 4.76 & $2.19-10.36$ & 22.0 & 5.73 & $2.66-12.37$ & 11.0 & 1.31 & 0.83-3.95 & 12.7 & 2.81 & $1.30-6.09$ \\
\hline Nagelkerke R-square & & & .061 & & & .077 & & & .011 & & & .078 & \\
\hline
\end{tabular}


in a healthcare profession and may therefore differ from that of the general working population independently of "true" differences between health statuses. A bias in both directions may occur; physicians may be more aware of their own health problems or may underestimate them, since they are confronted with sick patients every day. The tendency to give socially desirable answers may also be stronger in the physicians' sample than in the other samples due to their health-related work, which could be another possible explanation for the high percentage of physicians reporting very good health. Taking all these possible explanations together, the significantly higher prevalence of poor self-rated health may even be an underestimate. One important reason for the high percentage of physicians with moderate to very poor health might also be their high workload. A high workload may not only be associated with work-life conflict. It also has a direct impact on health status. A significant relationship between workload and health complaints was found by Tomuyuki and Ooya [39] and Krantz et al. [40]. Thus, the association between workload, work-life conflict and health needs a detailed analysis and should be addressed in a future study.

A significant association between work-life conflict and poor self-rated health was found consistently for physicians, university graduates and the general working population. The significant correlation between work-life conflict and ill health of $\mathrm{r}=.267(p<.001)$ for time-based conflict and $\mathrm{r}=.363(p<.001)$ for strain-based conflict, are consistent with findings from other studies on physicians: Fuss et al. [4] found a correlation of $r=-.26(p<.01)$ between work-family interference and health, and Geurts et al. [19] found a correlation of $\mathrm{r}=.37(p<.001)$ between worklife conflict and psychosomatic health complaints. In the present study, the negative association between work-life conflict and health was stronger for the strain-based form. However, significant associations were found for both forms. If both forms are analysed in the same logistic regression (i.e. controlling for each other), the association of the time-based form almost disappeared. Time-based worklife conflict seems to be less strongly associated with ill health.

For physicians, work-life conflict are a stronger predictor for ill health than for other university graduates or employees in general. The high odds ratio of 15.71 indicates that physicians experiencing strong strain-based worklife conflict are nearly 16 times more likely to report moderate to very poor general health. The strong association between work-life conflict and health in the physicians' sample may have different reasons. Profession may be a moderator variable in the association between work-life balance and health. As far as we know, this has not been found before. The more probable explanation for the high odds ratios in the physicians' sample may be the very small number of cases in the reference group (moderate to very poor health). Since more physicians suffer from strong work-life conflict, which are closely correlated with health, this may explain the fact that physicians report a worse health status than one would expect in view of their education and socio-economic status.

\section{Limitations and strengths}

- The physicians' sample represents a cohort that is homogenous with respect to age and stage of profession. Therefore, the results cannot be generalised to the whole Swiss medical profession. We can only draw conclusions for the analysed age group.

- Due to the cross-sectional design of the study, no causal assumptions may be drawn.

- Single items were used to assure comparability with the Swiss Household Panel.

- As exactly the same items were used to assess work-life conflict and health in the three (sub-) populations, it was possible to compare the samples of different data collections.

\section{Conclusion}

Strain-based work-life conflict is strongly related to health problems. Since physicians report an above average incidence of work-life conflict, this is a substantial problem for this profession as well as being a health risk. The high prevalence of work-life conflict and its strong association with poor health may explain the higher than expected prevalence of health complaints in the physicians' sample.

Additionally, as other studies have shown, strong worklife conflict is a predictor of lower commitment, lower job satisfaction and higher turnover rates [10]. Efforts should consequently be made to reduce the work-life conflict of physicians, not least to assure good healthcare services.

\section{Funding / potential competing interests}

The study was supported by grants from the Swiss National Science Foundation Program (No. 3200 BO-113836). It used data collected by the Swiss Household Panel, a project financed by the Swiss National Science Foundation Program SPP "Switzerland Towards the Future" (Grant No. 5004-53205)

\section{References}

1 Geurts SAE, Kompier MAJ, Roxburgh S, Houtman ILD. Does workhome interference mediate the relationship between workload and wellbeing? J Voc Behav. 2003;63:532-59.

2 Reichenbach L, Brown H. Gender and academic medicine: impacts on the health workforce. Br Med J. 2004;329:792-5.

3 Fox G, Schwartz A, Hart KM. Work-family balance and academic advancement in medical schools. Acad Psych. 2006;30(3):227-34.

4 Fuss I, Nübling M, Hasselhorn H-M, Schwappach D, Rieger MA Working conditions and work-family conflict in German hospital physicians: psychosocial and organisational predictors and consequences. BMC Public Health. 2008;8(353):1-17.

5 Bundesamt für Statistik BuW: Bildungsprozess Schweizerisches Hochschulinformationssystem (SHIS): Studierende und Abschlüsse. In.; 2009.

6 FMH-Ärztestatistik 2007 [http://www.fmh.ch/themen/aerztedemographie/aerztestatistik.html]

7 Greenhaus JH, Beutell NJ. Sources of conflict between work and family roles. Acad Manag Rev. 1985;10(1):76-88.

8 Kelloway EK, Gottlieb BH, Barham L. The source, nature, and direction of work and family conflict: A longitudinal investigation. J Occup Health Psychol. 1999;4(4):337-46. 
9 Gutek B, Searle S, L. K. Rational versus gender role-explanations for work-family conflict. J Appl Psychol. 1991;76:560-8.

10 Allen TD, Herst DEL, Bruck CS, Sutton M. Consequences associated with work-to-family conflict: A review and agenda for future research. J Occup Health Psychol. 2000;5(2):278-308.

11 Frone MR, Russell M, Barnes GM. Work-family conflict, gender, and health-related outcomes: A study of employed parents in two community samples. J Occup Health Psychol. 199;1(1):57-69.

12 Hämmig O, Bauer GF. Work-life imbalance and mental health among male and female employees in Switzerland. Int $\mathrm{J}$ Public Health. 2009;54(2):88-95.

13 Hämmig O, Gutzwiller F, Bauer GF. Work-life conflict and associations with work- and nonwork-related factors and physical and mental health outcomes: a nationally representative cross-sectional study in Switzerland. BMC Public Health. 2009, 9.

14 Demerouti E, Bakker AB, Bulters AJ: The loss spiral of work pressure, work-home interference and exhaustion: Reciprocal relations in a threewave study. J Voc Behav. 2004;64(1):131-49.

15 Peeters MCW, de Jonge J, Janssen PPM, van der Linden S. Work-home interference, job stressors, and employee health in a longitudinal perspective. Int J Stress Manag. 2004;11(4):305-22.

16 Dikkers JSE, Geurts S, Kompier MAJ, Taris TW, Houtman ILD, van den Heuvel F. Does workload cause work-home interference or is it the other way around? Stress and Health. 2007;23:303-14.

17 Britt TW, Dawson CR. Predicting work-family conflict from workload, job attitudes, group attributes, and health: A longitudinal study. Mil Psychol. 2005;17(3):203-27.

18 Biaggi P, Peter S, Ulich E. Stressors, emotional exhaustion and aversion to patients in residents and chief residents - what can be done? Swiss Med Wkly. 2003;133:339-46.

19 Geurts S, Rutte C, Peeters M. Antecedents and consequences of workhome interference among medical residents. Soc Sci Med. 1999;48(9):1135-48.

20 Montgomery AJ, Panagopolou E, Benos A. Work-family interference as a mediator between job demands and job burnout among doctors. Stress and Health. 2006;22(3):203-12.

21 Rovik JO, Tyssen R, Hem E, Gude T, Ekeberg O, Moum T, Vaglum P. Job stress in young physicians with an emphasis on the work-home interference: A nine-year, nationwide and longitudinal study of its course and predictors. Industrial Health. 2007;45:662-71.

22 Adam S, Györffy Z, Susanszky E. Physician burnout in Hungary: A potential role for work family conflict. J Health Psychol. 2008;13(7):847-56.

23 Buddeberg-Fischer B, Stamm M, Buddeberg C, Klaghofer R. The new generation of family physicians - career motivation, life goals and work-life balance. Swiss Med Wkly. 2008;138:305-12.

24 Töyry S, Räsänen K, Kujala S, Äärimaa M, Juntunen J, Kalimo R, et al. Self-reported health, illness, and self-care among Finnish physicians. Arch Fam Med. 2000;9(10):1079-85.
25 Lovell BL, Lee RT, Frank E. May I long experience the joy of healing: Professional and personal wellbeing among physicians from a Canadian province. BMC Fam Pract. 2009;10:18.

26 Frank E, McMurray JE, Linzer M, Elon L. Career satisfaction of US women physicians: Results from the woman physicians' health study. Society of general internal medicine career satisfaction study group. Arch Intern Med. 1999;159(13):1417-26.

27 Resch M, Hagge M. Ärztegesundheit - ein lange vernachlässigtes Thema. In.

28 Jurkat HB, Cramer M, Reimer C, Kupfer J, Gieler U. Gesundheitsbezogene Lebensqualität von Dermatologen im Vergleich zu anderen Arztgruppen. Hausarzt. 2007;58:38-47.

29 Buddeberg-Fischer B, Stamm M, Buddeberg C, Bauer G, Hämmig O, Klaghofer R. Arbeitsstress, Gesundheit und Lebenszufriedenheit junger Ärztinnen und Ärzte. Ergebnisse einer Schweizer Longitudinalstudie. Deutsche Medizinische Wochenschrift 2008;133:2441-7.

30 Buddeberg-Fischer B, Stamm M, Buddeberg C, Klaghofer R. Angst und Depression bei jungen Ärztinnen und Ärzten - Ergebnisse einer Schweizer Longitudinalstudie. Z Psychosom Med Psychother. 2009;55:37-50.

31 Buddeberg-Fischer B, Klaghofer R, Stamm M, Siegrist J, Buddeberg C. Work stress and reduced health in young physicians: prospective evidence from Swiss residents. Int Arch Occup Environ Health 2008;82:31-8.

32 Aasland O, G., Olff M, Falkum E, Schweder T, Ursin H. Health complaints and job stress in Norwegian physicians: the use of an overlapping questionnaire design. Soc Sci Med. 1997;45(11):1615-29.

33 Stavem K, Hofoss D, Aasland OG, Loge JH. The self-perceived health status of Norwegian physicians compared with a reference population and foreign physicians. Scand J Public Health. 2001;29:194-9.

34 Carlson DS, Kacmar KM, Williams LJ. Construction and initial validation of a multidimensional measure of work-family conflict. J Voc Behav. 2000;56(2):249-76.

35 Bird CE, Fremont AM. Gender, time use, and health. J Health Soc Behav. 1991;32(2):114-29.

36 Idler E, Benyamini Y. Self-rated health and mortality: a review of twenty-seven community studies. J Health Soc Behav. 1997;38:21-37.

37 Frone MR, Russell M, Cooper ML. Antecedents and outcomes of workfamily conflict: Testing a model of the work-family interface. J Appl Psychol. 1992;77(1):65-78.

38 Thompson CA, Prottas DJ. Relationships among organizational family support, job autonomy, perceived control, and employee well-being. $\mathrm{J}$ Occup Health Psychol. 2005;10(4):100-18.

39 Kawada T, Ooya M. Workload and health complaints in overtime workers: a survey. Arch Med Res. 2005;36(5):594-7.

40 Krantz G, Berntsson L, Lundberg U. Total workload, work stress and perceived symptoms in Swedish male and female with-collar employees. Eur J Public Health. 2005;15(2):209-14. 